\title{
Escolas de governo: tendências e desafios - ENAP-Brasil em perspectiva comparada ${ }^{1}$
}

Revista do

Serviço

Público

Ano 51

Número 2

Abr-Jun 2000

Regina Silvia Pacheco ${ }^{2}$

\section{Introdução}

O presente texto discute as escolas de governo latino-americanas, sua origem, evolução recente e perspectivas. Para tanto, reconstrói a história institucional da ENAP Escola Nacional de Administração Pública/Brasil, buscando levantar pistas de análise a serem testadas nas demais escolas. A fim de suscitar o debate, arrisca algumas generalizações para o contexto latino-americano - como a tentativa de periodização e a análise dos anos 80. Não tem por objetivo propor a convergência dos modelos e orientações das várias escolas de governo latino-americanas; apenas quer suscitar uma reflexão de conjunto que aponte traços comuns, para ajudar a contextualizar e ampliar o debate que se trava em cada país sobre as perspectivas destas escolas de governo.

O texto está organizado em sete partes. Inicia adotando uma definição para o termo "escola de governo", para fins de análise neste texto, já que seu uso corrente é vago e impreciso. A seguir, reconstrói a trajetória institucional da ENAP-Brasil, a fim de estabelecer alguns parâmetros para a análise em perspectiva comparada. Na terceira parte, entra na análise comparada, arriscando uma periodização para a história recente das escolas de governo (pós-80). Na quarta parte, analisa as escolas de governo latinoamericanas nos anos 80, discutindo a influência do "paradigma ENA". Em seguida, apresenta e discute a tese de que, hoje, não cabe mais a análise em termos continentais (escolas latino-americanas x européias e norte-americanas), pois surge um novo agrupamento de tipos de escola, segundo a orientação que assumem frente a alguns temas centrais; para tanto, expõe e analisa a missão de nove escolas de governo. Na sexta

Regina Silvia Pacheco é presidente da ENAP Escola Nacional de Administração Pública/Brasil.

Professora doutora da

Fundação Getúlio Vargas, São Paulo (licenciada) 
parte, apresenta as atuais tendências das escolas de governo dos países da Commonwealth, discutindo desafios e oportunidades para as instituições latino-americanas. Finalmente, nas conclusões, sintetiza e discute desafios, estratégias e perspectivas para as escolas de governo.

\section{Escolas de governo: um termo impreciso}

O termo "escola de governo" admite várias definições; vem sendo usado indistintamente por organizações públicas, privadas ou não governamentais, destinadas à formação de quadros, reciclagem de funcionários ou ainda fóruns de debate, especialmente para os poderes Executivo e Legislativo, nas três esferas de governo. Assim, o termo abriga usualmente instituições muito diversas; podemos identificar pelo menos as seguintes:

- universidades com cursos de graduação e pós-graduação onde os egressos buscam, por conta própria, sua colocação no mercado de trabalho público ou privado;

- instituições estatais ou fortemente financiadas pelo Estado voltadas à seleção e formação inicial de quadros e/ou reciclagem de funcionários;

- instituições que fornecem cursos de especialização, mediante pagamento, ou mesmo ciclo de atualização e debate para candidatos e quadros políticos.

Diante desta imprecisão, fica vago o debate sobre evolução e tendências das escolas de governo. Assumimos como "escolas de governo" neste texto, para fins de análise, aquelas instituições destinadas ao desenvolvimento de funcionários públicos incluídas no aparato estatal central (nacional ou federal) ou fortemente financiadas por recursos orçamentários (INAP do México, por exemplo). Isto porque sua inserção no aparelho estatal tem fortes implicações para o debate em torno de sua missão, finalidades e desafios.

\section{Breve histórico da ENAP-Brasil}

\section{Origens: a inspiração francesa}

A ENAP foi criada em 1986, como uma Diretoria, dentro de uma instituição já existente - a FUNCEP, organização de estatuto privado sem fins lucrativos, financiada pelo Governo Federal, criada em 1980 e dedicada ao treinamento de servidores públicos federais. Em 1990, a instituição se torna uma fundação pública e passa a se chamar ENAP. 
A ENA - École Nationale d’Administration foi claramente a referência para a criação da ENAP em 1986. Tendo por base um relatório de 1982 (Relatório Rouanet), que estudou os modelos francês e alemão, a ENAP é criada com a missão de preparar quadros de nível superior, tendo por modelo a ENA francesa. Durante seus primeiros 3 ou 4 anos, a ENAP recebeu regularmente consultoria de diretores da ENA: "vale observar que a ENA velava, por assim dizer, para que sua congênere brasileira se afastasse o mínimo possível do modelo francês" (ENAP, 1995: 97).

É importante salientar que a visão predominante, quando da criação da ENAP em 1986, via a constituição de corpos permanentes de carreira como a principal estratégia de modernização ou reforma do setor público. No contexto de redemocratização do país, após mais de duas décadas de ditadura militar, a transição democrática no Brasil conviveu com o retorno do clientelismo e com expressões de populismo; assim, no cenário que marcou os preparativos para a Assembléia Constituinte de 1987-88, imperou a desconfiança generalizada nos administradores públicos e a visão de que "face à inoperância do setor público, é necessário mais burocracia" (Pacheco, 1999: 100).

Este foi o sentido dado à profissionalização do setor público, o que representou, concretamente, um retorno à agenda dos anos 1930 e à primeira tentativa de criação de uma burocracia profissional e permanente. No caso do Brasil, podemos claramente falar de um "retorno" ou "retrocesso", posto que a administração pública brasileira havia experimentado uma orientação para a flexibilização a partir da reforma administrativa de 1967 (odecreto-lei 200), que vigorou durante os anos 70 e a primeira metade dos 80 .

Poderíamos dizer que a segunda metade dos anos 80 representou portanto, para a agenda de reformas da administração pública, um grande retrocesso. Referindo-se ao capítulo da administração pública na Constituição (do Brasil) de 1988, Bresser Pereira (1996: 14-15) afirma que "os constituintes e, mais amplamente, a sociedade brasileira revelaram nesse momento uma incrível falta de capacidade de ver o novo. Perceberam apenas que a administração burocrática clássica, que começara a ser implantada no país nos anos 30, não havia sido plenamente instaurada. E decidiram completar a revolução burocrática antes de pensar nos princípios da moderna administração pública".

\section{Dois conflitos iniciais: \\ escola de governo $x$ universidade; formação $x$ capacitação}

Quando da criação da ENAP-Brasil, houve conflito com universidades, que não concordavam com a criação de escolas de governo fora 
do sistema universitário (ENAP, 1995: 97). De fato, o projeto adotado para a ENAP visava se contrapor às universidades, pois considerava que a formação de quadros para o Estado só podia ser realizada por uma instituição que tivesse essa finalidade específica, situada dentro do aparelho do Estado, tendo por base a visão de que as universidades não cumpririam este papel. Este aspecto demonstra mais uma vez a inspiração francesa que orientou a criação da ENAP.

Por outro lado, a decisão de criar a ENAP como uma diretoria ("um enclave" - ENAP, 1995: 95-96) dentro de outra instituição pré-existente, voltada ao treinamento de servidores de níveis operacional e intermediário, trouxe problemas de cultura organizacional que persistiram até os anos 90: uma grande dicotomia entre formação (de quadros de alto nível) e treinamento ou capacitação (de servidores menos qualificados). Outro problema decorreu da estratégia de contratação de equipe externa para a Diretoria ENAP (profissionais de ciências humanas com mestrado), o que contribuiu para o clima de "duas culturas" e o elitismo da ENAP.

Estes dois conflitos vão marcar a evolução da ENAP. A oposição entre formação e capacitação acabou levando ao desprestígio das atividades de capacitação e mesmo ao imobilismo institucional quando, na primeira metade dos anos 90, o Governo Federal deixou de realizar concursos de ingresso para o setor público. Além disso, disseminou-se um clima organizacional pautado em duas culturas distintas, uma prestigiosa e de elite, voltada à formação de quadros para carreiras; outra desmotivada, pouco atuante e "parada no tempo" (seus quadros não se desenvolveram profissionalmente), voltada à capacitação.

\section{Início dos anos 90: imobilismo}

Na primeira metade dos anos 90 a ENAP, assim como muitas outras instituições públicas federais, sofreu da falta de definição de um projeto institucional claro, das alterações freqüentes de direção, convergindo para um imobilismo e pequena expressão de suas atividades. No caso da ENAP, estas características decorreram da ausência de uma política clara para a reforma da administração pública - que só vai entrar na agenda do país a partir de 1995. No início dos anos 90, o governo impulsionou a primeira onda de reforma do Estado, baseada na privatização, quebra de monopólios estatais e desregulamentação; quanto ao aparelho de Estado, no entanto, não havia uma proposta clara de reforma, e sim estratégias claras de desmonte (governo Collor), seguidas de políticas salariais generosas e tentativa de angariar apoio junto às camadas do funcionalismo (governo Itamar).

A não-realização de concursos de ingresso para a administração pública federal, neste período, frustrou o "lado nobre" das atividades da ENAP (formação inicial para carreiras do Estado); por outro lado, as 
atividades de capacitação e reciclagem, desprestigiadas mesmo internamente na ENAP, reduziram-se a níveis pouco expressivos. Assim, frente à média histórica de cerca de 2.000 treinamentos/ano, a ENAP reduziu sua realização a 340 treinamentos em 1990 e 747 treinamentos em 1991.

Durante os anos 1993-94, a ENAP ensaiou adentrar em temas da reforma política (por exemplo, promovendo eventos sobre o parlamentarismo e a revisão constitucional) e tentou defender a visão tradicional (burocrática) de profissionalismo no setor público baseado em um sistema de carreiras e na ética da moralidade.

\section{ENAP e a reforma do Estado a partir de 1995}

Com o governo Fernando Henrique Cardoso, a partir de 1995, a reforma da administração pública entra na agenda do país. Cria-se o MARE - Ministério da Administração Federal e Reforma do Estado, tendo à frente o Ministro Bresser Pereira, que formulou e difundiu as propostas de reforma gerencial, realizando um verdadeiro aggiornamento da agenda de reforma do aparelho de Estado.

Neste período, a ENAP, vinculada ao MARE, ajudou a formular e difundir as novas proposições para a reforma do setor público. Adotou o conceito de "educação continuada" e aplicou-o na capacitação de diversos segmentos de funcionários (das áreas administrativas, gerentes operacionais e intermediários), tendo capacitado, entre 1995 e 1999, mais de 72.000 servidores públicos federais - isto significa que em cinco anos, capacitou quase 3 vezes mais funcionários do que nos catorze anos anteriores. Assumiu, em seus cursos, a orientação de preparação para a mudança.

A reforma adotada para o setor público visava ao mesmo tempo promover a nova administração pública e fortalecer o núcleo estratégico do Estado com a retomada de concursos públicos para as carreiras que compõem este núcleo. Assim, a ENAP retomou suas atividades de formação inicial para carreiras, tentando imprimir o sentido de "agentes de mudança" também aos novos ingressantes em carreiras; entre 1995 e 1999, formou 393 especialistas em políticas públicas e gestão governamental (4 promoções) e 219 analistas de planejamento e orçamento (3 promoções).

$\mathrm{Na}$ área da pesquisa e difusão, reorientou suas atividades de pesquisa para a pesquisa aplicada, distinta da realizada pelo sistema acadêmico, e focada em temas ligados à melhoria da gestão pública. Deu o mesmo foco às suas publicações e à política de especialização do acervo de sua biblioteca. Passou a realizar um concurso anual de inovações na gestão pública federal, captando e divulgando experiências já implementadas, pautadas nos princípios da nova administração pública. 
A partir de janeiro de 1999, houve a fusão entre o Ministério da Administração Federal e Reforma do Estado e o Ministério do Planejamento e Orçamento, resultando no novo Ministério do Planejamento, Orçamento e Gestão, ao qual se vincula a ENAP. O governo adota a integração entre planejamento, orçamento e gestão e formula o Plano Plurianual PPA 20002003, onde todas as atividades do governo federal são estruturadas em programas.

O Plano Plurianual adota a gestão por programas para assegurar maior transparência e responsabilização gerencial. Assim, o governo espera atender às demandas da sociedade por melhores serviços públicos, com custos reduzidos. A intenção é realizar a alocação estratégica de recursos, para promover o desenvolvimento sustentável do país, ao mesmo tempo em que se confere melhor qualidade ao gasto público.

Cada programa tem um objetivo claro, metas anuais e recursos estimados, bem como indicadores de resultado, tendo à frente um gerente, responsável pelos resultados do programa e pela otimização dos recursos a ele alocados. Assim, todas as ações resultaram na definição de 380 programas, construídos a partir de orientações estratégicas do governo.

Neste contexto, coube à ENAP o programa "Desenvolvimento de Gerentes e Servidores Públicos", trazendo como principal novo desafio apoiar os dirigentes e os gerentes estratégicos dos 380 programas do PPA.

Este desafio se desdobra em novas orientações para a ENAP:

- trabalhar com um público-alvo novo, mais exigente e crítico, com grandes constrangimentos de tempo a dedicar à capacitação;

- conhecer a nova clientela e identificar segmentos específicos quanto às necessidades de desenvolvimento em gestão;

- passar da "oferta de cursos" à produção e difusão de conhecimento e tecnologia gerencial (diversificar os produtos) e a programas de desenvolvimento gerencial (com atividades pré e pós-curso e novas metodologias de aprendizagem);

- prospectar o conhecimento de ponta em gestão (conceitos, técnicas e ferramentas; especialistas; instituições de excelência), desenvolvido para o setor privado, e adaptá-lo para as especificidades do setor público;

- buscar parcerias em novas bases com universidades, empresas de consultoria e consultores nacionais, bem como com centros internacionais de excelência de desenvolvimento de dirigentes no setor público;

- produzir informação sistemática sobre o funcionamento da administração pública brasileira, e difundi-la junto a dirigentes, gerentes estratégicos, pesquisadores e formadores de opinião;

- antecipar tendências e identificar melhores práticas em nível internacional, para promover o benchmarking; 
- buscar influir nas políticas de recursos humanos e desenvolvimento gerencial;

- continuar a formar quadros para as carreiras de Estado, reforçando suas competências como agentes de mudança;

- difundir a metodologia do Plano Plurianual junto aos governos estaduais;

- desenvolver competência interna em desenvolvimento gerencial, aprendendo com os parceiros, ao mesmo tempo em que atende aos novos públicos-alvo;

- promover a transição interna para os novos desafios, articulando o desenvolvimento de dirigentes e gerentes estratégicos às atividades de educação continuada de outros segmentos de servidores públicos.

\section{Escolas de governo em perspectiva comparada: tentativa de periodização}

Os períodos de criação das escolas de governo variaram, tanto nos países da Europa como na América Latina ${ }^{3}$. No entanto, podemos falar em três períodos onde há convergência de tendências:

- nas instituições latino-americanas, há uma coincidência nos anos 80 em termos de reforma de programas e reorientação, a maioria das quais tendo por inspiração o modelo francês da ENA École Nationale d'Administration;

- nas instituições européias, uma reorientação no final dos anos 80, em geral marcando um afastamento com relação ao paradigma francês (a própria ENA tem seu modelo bastante criticado a partir de meados dos anos 80) e uma orientação para o New Public Management e as reformas gerenciais $^{4}$;

- no contexto da América Latina, parece haver uma nova onda de reorientação das escolas de governo, a partir da segunda metade ou do fim dos anos 90, na mesma direção da reforma gerencial.

O que queremos discutir não é o provável descompasso, nos anos 80, entre as tendências observadas nas escolas de governo da Europa e América Latina, e sim os conteúdos das mudanças, suas inspirações e desdobramentos, especialmente no âmbito latino-americano.

Enquanto buscávamos, na América Latina, construir maior solidez burocrática, os países desenvolvidos reformavam suas instituições para uma nova administração pública, marcada pela descentralização, flexibilização, responsabilização de gerentes e dirigentes, contratualização de resultados e meios, competição administrada, transparência, novas formas de controle de resultados — a New Public Management. 
Respeitadas as trajetórias históricas, não cabe falar em descompasso ou atraso dos países latino-americanos; trata-se antes de compreender as causas desta evolução, e tirar as lições para os próximos passos.

\section{Escolas de governo latino-americanas: os anos 80 e o modelo ENA}

O estudo realizado pela ENAP em 1994 e publicado em 1995 apontava que os INAPs da Argentina e México (e da Espanha) e a ENAP do Brasil, em seus programas dos anos 80 (período enfocado pelo estudo), adotaram, "pelo menos inicialmente, o modelo de formação da École Nationale d'Administration - ENA" (ENAP, 1995: 11). Ao longo do texto, ficam explicitadas as inspirações para tanto:

- superar a tradição de recrutamento político e clientelista que marcou as administrações públicas latino-americanas (op.cit: 227);

- "suprir deficiências resultantes de um funcionalismo que não se encontra pautado num sistema de carreiras e tampouco num sistema de mérito" (op.cit: 58);

- assegurar menor descontinuidade administrativa (op.cit: 227).

Tratava-se, em síntese, de "profissionalizar a administração pública nacional" (op.cit: 38). No fundo, este era o conteúdo dado ao termo "profissionalização no setor público" nos anos 80, na América Latina: a constituição de corpos permanentes, compostos por servidores estáveis, organizados em carreiras, recrutados por concurso público e promovidos por mérito e antigüidade. Esta visão era predominante tanto no debate político, como no ambiente acadêmico e também junto às escolas de governo.

Com esta inspiração, o sistema francês figurou como o principal referencial, ao ter as seguintes características, segundo a visão dominante à época: "corrige o uso clientelista da administração pública, prepara competências e evita descontinuidades administrativas em transições políticas" (op.cit: 17), além de formar generalistas com mobilidade horizontal, "evitando, assim, o estancamento entre os ministérios e a formação de castas profissionais" (op.cit: 17).

Como se observou no período que se seguiu, a transposição do modelo francês foi frustrada. Em parte, porque o modelo não era tão virtuoso como imaginado e propalado, como demonstram os últimos $10 \mathrm{ou}$ 15 anos de críticas à ENA e as tentativas de reformulação deste modelo. E mais profundamente porque os Estados e as sociedades latino-americanas têm características e problemas distintos, colocando limites à transposição de modelos.

Como já apontado para o caso brasileiro, tais tentativas de importação do modelo ENA representaram a busca de construção de uma burocracia 
tradicional sólida, enquanto vários países já se lançavam na reforma das burocracias. Também extemporânea era a idéia de nítida separação entre política e administração, entre políticos e burocratas, em contextos cada vez mais democráticos 5 .

\section{Situação atual: nova convergência entre escolas de governo?}

De qualquer forma, arriscamos afirmar que há hoje uma convergência em termos de missão e finalidades de algumas escolas de governo, tanto nos países norte-americanos e europeus como no contexto latinoamericano. Podemos agrupar as diferentes escolas de governo segundo esta convergência de missões, e veremos que não é mais possível falar em "tendências continentais" (latino-americanas x européias e norte-americanas); as diferenças referem-se hoje a alguns dos temas centrais para as escolas de governo:

- autonomia ou alinhamento às estratégias de governo;

- preparação de quadros para a continuidade ou para a mudança;

- conteúdo dado aos termos "modernização" e "profissionalização" do setor público: ênfase em carreiras ou em gerentes e líderes;

- abordagem acadêmica ou profissionalizante;

- atividades exclusivas de formação/capacitação ou combinadas com pesquisa aplicada e difusão.

Isto pode ser observado a partir da missão afirmada pelas diferentes instituições.

É possível identificar um grupo de instituições que reúnem as seguintes características:

- afirmam seu alinhamento às estratégias do governo ou colocamse como apoio às mudanças que se quer produzir no setor público;

- desempenham, ao mesmo tempo, uma função de antena e antecipação de tendências;

- especificam o conteúdo dos termos modernização e profissionalização com os princípios da nova gestão pública, explicitando, inclusive, ser o cidadão o destinatário final da modernização do setor público;

- dão ênfase ao desenvolvimento gerencial e à liderança como alavancas da mudança e da inovação;

- e buscam metodologias aplicadas ao desenvolvimento profissional, afastando-se da abordagem acadêmica.

Incluímos neste grupo: CCMD - Canadá, CSC - Grã-Bretanha, ENAP-Brasil e SIFOM — França. Vejamos a missão de cada uma destas instituições: 
CCMD Canadian Centre for Management Development, Canadá

"Apoiar as necessidades de desenvolvimento gerencial dos gerentes do serviço público por meio de programas de aprendizagem e cursos, eventos de aprendizagem, pesquisa estratégica e outras atividades de desenvolvimento de liderança para que, como uma comunidade, os servidores públicos sejam capazes de enfrentar os desafios de seu tempo no cumprimento da sua missão de servir o Canadá e os canadenses." (Catálogo 2000).

\section{CSC Civil Service College,}

\section{Grã Bretanha}

"O Civil Service College tem um papel crucial na implementação de partes importantes da visão e estratégia do Centro para Estudos de Gerenciamento e Política (CMPS) ${ }^{6}$.

Em apoio ao Programa de Modernização do Governo, o CMPS possui dois objetivos principais:

Criar um novo conjunto de recursos para fortalecer a elaboração de políticas públicas; e

Desenvolver uma nova geração de servidores públicos com o necessário conhecimento, habilidades e comportamento requeridos pela moderna elaboração de políticas públicas e oferta de serviços.

O Civil Service College possui reconhecida experiência de treinamento, desenvolvimento e consultoria (nacional e internacionalmente) para colaborar na consecução desses objetivos." (Internet).

\section{ENAP Escola Nacional de Administração Pública, Brasil}

"A ENAP tem por finalidade buscar e difundir conhecimento e tecnologia gerencial para o desenvolvimento de dirigentes, gerentes e demais servidores públicos, em direção à gestão pública ágil, eficiente e com foco no cidadão.

Vinculada ao Ministério do Planejamento, Orçamento e Gestão, a ENAP busca traduzir, em seus programas, as orientações de governo para a inovação na gestão pública. Para tanto, investe em conhecimento e tecnologia gerencial de ponta, buscando adaptá-los à melhoria da gestão pública." (Catálogo 2000-2001).

\section{SIFOM Secteur Interministériel de Formation à l’Organisation et au Management, França}

"Acompanhar, antecipar e promover a modernização dos serviços de Estado por meio de atividades de formação e de consultoria. 
Dadas suas ações interministeriais, o SIFOM ocupa uma posição privilegiada de observatório das evoluções do setor público. O SIFOM é ligado ao CFPP, que depende da Direção de Pessoal, da Modernização e da Administração do Ministério da Economia, Finanças e Indústria.

Os serviços do SIFOM têm por objetivos melhorar as práticas, permitir a cada um se interrogar sobre o sentido de suas ações, transferir seus novos conhecimentos às situações de trabalho, e favorecer uma reflexão de alto nível articulada ao contexto profissional de seus clientes." (Catálogo 2000).

As demais instituições merecem comentários específicos.

- As escolas de governo de Portugal e Espanha fazem referência ao compromisso com a modernização da administração pública, sem no entanto explicitar que sentido conferem a esta modernização. Com relação aos demais aspectos, cabe ressaltar que o INA - Portugal destaca, em sua missão, sua autonomia ("científica, administrativa e financeira"), o que pode indicar um desejo de distanciamento com relação às políticas de governo; já o INAP - Espanha afirma ser o "centro da administração geral do Estado", o que talvez denote uma maior proximidade com as políticas de governo (ainda que conceitualmente não se possa confundir Estado e governo):

\section{INA Instituto Nacional de Administração, Portugal}

"O INA é um instituto público, com autonomia científica, administrativa e financeira, que possui o objetivo de contribuir para o esforço de modernização da administração pública através da Formação, da Investigação e da Assessoria Técnica." (Internet).

\section{INAP Instituto Nacional de Administración Pública, Espanha}

"O Instituto Nacional de Administração Pública (INAP) é o centro da Administração Geral do Estado responsável pela seleção e formação de dirigentes e servidores públicos, e que realiza ainda tarefas de pesquisa e estudos a serviço do processo de modernização da Administração Pública." (Internet).

- A instituição mexicana coloca a sociedade como seu cliente direto, e o Estado como cliente derivado; é uma proposição arrojada, que no entanto deve implicar sérias dificuldades para a avaliação dos resultados de suas ações. Destaca o compromisso com a promoção da ética, da moralidade, e adota os propósitos de eficiência e eficácia para o Estado; deixa, porém, de explicitar o conteúdo dado à profissionalização no setor público: 
INAP Instituto Nacional de

\section{Administración Pública, México}

"Servir à sociedade contribuindo para que o Estado que a representa seja eficaz e eficiente e conte com uma administração pública moderna, honesta e profissional." (Internet).

- O INAP da Argentina amplia sua clientela para dirigentes políticos e sociais, adotando o pluralismo ideológico (para marcar distância dos governos?) e a abordagem acadêmica (como se situa no mundo universitário?); quanto à administração pública, afirma trabalhar pelo fortalecimento democrático (como medir o impacto?), e deixa de explicitar o conteúdo dado à profissionalização:

\section{INAP Instituto Nacional de} Administración Pública, Argentina

"Formar e capacitar em um ambiente de pluralismo ideológico e excelência acadêmica os dirigentes políticos e sociais.

Melhorar e aprofundar o fortalecimento institucional democrático mediante uma gestão profissional das questões de Estado." (Internet).

- Finalmente, a ENA — França ocupa um lugar à parte, ao afirmar seu compromisso com a preparação da futura elite do setor público:

\section{ENA Ecole Nationale d'Administration, França}

"Formar altos funcionários e preparar seus alunos de carreiras para ocupar altos postos da administração francesa." (Catálogo 1998).

Embora não exaustiva, a análise das diferentes escolas de governo a partir de suas missões aponta pistas para repensar as tendências e desafios destas instituições. A tentativa de novo agrupamento das escolas de governo, em função de seus posicionamento e orientação estratégicos, indica algumas convergências e possibilidades de cooperação a serem exploradas.

\section{Tendências e desafios para as escolas de governo}

Borins (2000) publicou recentemente uma síntese de um seminário realizado em abril de 1999, reunindo representantes de dez países ${ }^{7}$ integrantes da Commonwealth Association for Public Administration and 
Management, onde foram discutidos tendências e desafios na capacitação de gerentes públicos. As principais tendências identificadas foram:

- uma competição crescente entre escolas de governo (civil service colleges) e fornecedores de capacitação externos;

- mudança de perfil das instituições universitárias que competem neste mercado: antes baseadas em departamentos de ciência política, agora baseadas em escolas de negócios;

- convergência, entre fornecedores de capacitação, no uso de metodologias aplicadas à educação de adultos;

- maior abrangência dos programas de desenvolvimento gerencial, antes voltados ao desenvolvimento de dirigentes e gerentes estratégicos (elite programs), agora abrangendo o conjunto do setor público em seus vários níveis gerenciais;

- algumas escolas de governo (na definição por nós adotada) atuando de forma mais integrada com prioridades estratégicas de governo e ao mesmo tempo desenvolvendo uma importante atividade de pesquisa, ocupando um papel comparável ao das universidades neste campo.

No conjunto, estas tendências refletem o alinhamento das escolas de governo aos princípios do New Public Management, ao mesmo tempo em que indicam a relevância atual do NPM para a capacitação. De fato, a busca de maior autonomia e responsabilização dos gerentes públicos, no contexto das reformas gerenciais, tornou "a capacitação uma ferramenta essencial" (Borins, 2000: 309). Na última década, cresceram os investimentos públicos em capacitação, ao mesmo tempo em que a avaliação concreta de resultados destes investimentos, para saber se a capacitação está realmente agregando valor. A competição entre fornecedores estatais e externos favorece uma maior capacidade de resposta às necessidades, tanto por parte das escolas de governo como pelos fornecedores externos.

A partir destas observações, poderíamos agregar que o monopólio de escolas de governo na capacitação de agentes públicos, tantas vezes defendido nos anos 80 , deixa de ser desejável ou salutar. Isto implica que as escolas de governo aceitem e pratiquem um dos princípios da nova administração pública, a competição, abrindo-se ao benchmarking e à comparação de resultados, bem como introduzindo métodos de gerenciamento de custos e de avaliação de impacto ou mensuração da satisfação das organizações clientes - novos temas para uma comunidade de psicólogos e pedagogos que constituem em geral a força de trabalho destas instituições.

A mudança de perfil das instituições universitárias que competem neste mercado (dos departamentos de ciência política para as escolas de negócios) pode representar uma nova oportunidade de interação para 
as escolas de governo com a universidade. Isto porque não é possível transpor, simplesmente, os conceitos e ferramentas aplicáveis às empresas privadas, para alavancar o melhor desempenho das organizações públicas. Assim, pode-se imaginar que caiba às escolas de governo prospectar o que há de melhor em conhecimento e tecnologia gerencial, sabidamente desenvolvidos com antecedência para o setor privado, e contextualizar este know-how às especificidades das organizações públicas.

Quanto às novas metodologias para educação de adultos, cabe destacar a liderança do CCMD - Canadian Centre for Management Development neste campo. O CCMD vem usando com sucesso o coaching e o mentorato, inseridos em programas de desenvolvimento gerencial, que abrangem atividades de pré e pós-curso, concebidos como programas de aprendizagem.

A quarta tendência indicada - top-down no desenvolvimento de gerentes - parece apresentar-se inversamente para o contexto latinoamericano. Escolas de governo como a ENAP, que nos últimos cinco anos promoveram a capacitação maciça de vários segmentos de servidores públicos, devem agora fazer o caminho bottom-up: o novo desafio é apoiar o desenvolvimento de dirigentes e gerentes estratégicos.

Este novo desafio implica rever várias das concepções que marcaram as escolas de governo latino-americanas durante os anos 80: revisar seu mito de fundação e repensar a relação entre escolas de governo e governo. Podemos desdobrar este desafio nos seguintes aspectos:

- por um lado, significa adotar um novo conceito de "profissionalização no setor público", baseado na importância da liderança e na efetividade gerencial, e não mais centrado apenas na idéia de servidores estáveis de carreira;

- significa ainda uma mudança de timing: antes as escolas de governo pretendiam formar as futuras elites administrativas; agora, devem apoiar os atuais dirigentes e gerentes estratégicos, e agregar valor imediato à melhoria de desempenho das organizações públicas;

- por último, para cumprir seu novo papel, as escolas de governo têm de ter maior integração aos desafios estratégicos do governo, ao mesmo tempo em que devem antecipar tendências no setor público.

Este último aspecto já foi apontado como uma das tendências por Borins. Ainda aqui, há uma nova oportunidade para as escolas de governo, por comparação às universidades. Isto porque, como afirma Borins (2000: 303), "enquanto a universidade tradicional procura se manter à distância do poder, de maneira que seus professores possam 'falar francamente ao poder', CCMD - Canadá e CMPS - UK estão tentando maior proximidade com o poder, associando-se com agências centrais e com as prioridades estratégicas do governo". 


\section{Conclusões: estratégias e perspectivas}

A reforma da administração pública, em direção a maior compromisso com resultados, eficiência e eficácia das ações de governo, abre grandes oportunidades para as escolas de governo. Um Estado ágil, eficiente e voltado para os cidadãos, necessita de gerentes, que compartilhem a ética, os valores e as competências gerenciais específicas para o setor público. Em muitos países, este conhecimento e tecnologia gerencial não estão desenvolvidos para o contexto das organizações públicas; assim, pode caber às escolas de governo promover a gestão do conhecimento em gestão pública, incentivando as parcerias, as comunidades de aprendizagem e o benchmarking.

Para aproveitar esta oportunidade, as escolas de governo devem posicionar-se frente a algumas questões centrais, como apontadas anteriormente: revisar seu "mito de fundação", ancorado na construção de corpos burocráticos; repensar sua relação com o governo ao mesmo tempo em que antecipam tendências e influenciam as políticas públicas para a administração; assumir uma ação afirmativa quanto à necessidade de desenvolvimento gerencial no setor público; engajar-se na promoção de mudanças; adotar metodologias próprias, voltadas à aprendizagem permanente de adultos profissionais, sem querer confundir-se com as instituições acadêmicas; competir com as universidades na produção do saber aplicado, na prospecção do conhecimento e tecnologia gerenciais adaptados às especificidades do setor público; esforçar-se para agregar valor imediato para o melhor desempenho das organizações públicas, e não apenas apostar na formação de futuras elites.

Novos temas devem ser abordados, referentes à gestão. Nos anos 80, as escolas de governo trabalhavam com temas de "administração" (recursos humanos, compras, orçamento e finanças, ...) ou de "políticas públicas" (saúde, educação, previdência...); devem agora se voltar para o ciclo da gestão, que abrange planejamento / formulação, implementação / monitoramento, e avaliação - de processo, de resultados (outputs) e de impacto (outcomes).

Para tanto, algumas estratégias mostram-se adequadas. Ferramentas como o balanced scorecard e o plano gerencial permitem articular os novos desafios e promover as várias transições necessárias — a transição das competências internas (dos profissionais das escolas de governo), a transição do produto (da "capacitação" à informação e conhecimento em gestão e aos programas de aprendizagem). Uma análise cuidadosa dos stakeholders é necessária, assim como a análise dos riscos e a gestão de riscos. É preciso desenvolver e aplicar ferramentas de marketing, específicas para o ambiente das organizações públicas, tais como segmentação 
dos públicos-alvo, fidelização dos colaboradores eventuais (muitas escolas de governo não dispõem de um corpo permanente de professores), benchmarking, atendimento customizado e resposta a demandas, avaliação da satisfação das organizações clientes e dos stakeholders. O trabalho em rede com pessoas e centros de excelência e as parcerias internacionais podem também ajudar a enfrentar os novos desafios.

A fim de garantir efetividade a suas ações, as escolas de governo, em perspectiva, devem buscar integração permanente com seus stakeholders. Devem ainda buscar atrair, para seus quadros, novos perfis profissionais, que aliem conhecimento sólido e experiência gerencial — os "arquitetos da aprendizagem gerencial". E lutar por maior flexibilidade no uso de recursos, assumindo em contrapartida compromissos com metas e resultados. Talvez caminhem para o desenvolvimento de poucos programas, voltados ao desenvolvimento gerencial, mas que sejam aplicados a grandes contingentes e vários níveis gerenciais, a fim de promover maior impacto de suas ações.

Quaisquer que sejam as estratégias adotadas, sabem hoje as escolas de governo que precisam provar que agregam valor à modernização da administração pública, requisito dos governos e crescentemente das sociedades.

\section{Notas}

1 Texto apresentado ao V Congresso Internacional do CLAD, no âmbito do painel "Evaluación comparada de los desafios, estrategias y perspectivas de desarrollo de los institutos nacionales de administración pública en Iberoamerica". Agosto de 2000.

2 Presidente da ENAP Escola Nacional de Administração Pública/Brasil. Professora doutora da Fundação Getúlio Vargas, São Paulo (licenciada). Para comentários: regina.pacheco@enap.gov.br

3 Na Europa, com exceção das precoces ENA — França (1945) e Speyer — Alemanha (1947, criada pelo Comando de Ocupação Francesa), os anos 60 parecem ter marcado a origem da maioria das escolas de governo (Bélgica - 1961, Dinamarca - 1963, Espanha - 1961, Irlanda - começo dos anos 60, Itália - 1957, Inglaterra - 1970), outra exceção, tardia, foi Portugal — 1979. Ver Zanghi, 1994. Na América Latina, as datas de criação são mais variadas: México/INAP - 1955, Argentina/INAP - 1973, Brasil/ ENAP - 1981. Ver ENAP, 1995.

4 O conceito de New Public Management foi longamente discutido pela literatura internacional. Ver, entre outros: Barzelay, 1992; Bresser Pereira, 1996.

5 A respeito das relações entre políticos e burocratas nas democracias ocidentais, ver Aberbach, Putnam e Rockman (1981).

6 No governo Blair, o Civil Service College foi incorporado ao CMPS.

7 Países presentes ao seminário: Austrália, Canadá, Grã-Bretanha, Singapura, Camarões, India, África do Sul, Uganda, Barbados e Malta. 


\section{| Referências bibliográficas}

Aberbach, J.D., Putnam, R.D., Rockman, B.A. (1981), Bureaucrats and politicians in Western Democracies. Mass: Harvard University Press.

BARZELAY, Michael. (1992), Breaking Through Bureaucracy: A New Vision for Managing in Government. Berkeley: University of California Press.

Borins, Sandford. (2000), "Trends in training public managers: a report on a Commonwealth Seminar", International Public Management Journal, 2(2(A)), p. 299-314

Bresser Pereira, Luiz Carlos. (1996), "Da administração pública burocrática à gerencial", Revista do Serviço Público 120(1), p. 7-39.

Della Cananea, Giacinto. (1998), “L’expérience de la Haute École d'Administration Publique en Italie", Revue Française d'Administration Publique, 87, p. 433-442.

ENAP. (1995), Escolas de Governo e profissionalização do funcionalismo. Relatório de Pesquisa. Brasília: ENAP, 253 p.

PACHECo, Regina Silvia. (1999), "Proposta de reforma do aparelho de Estado no Brasil: novas idéias estão no lugar" in Petrucci; Schwarz (orgs), Administração Pública Gerencial: a Reforma de 1995. Brasília: Editora da Universidade de Brasília e ENAP, p. 97-122.

Zanghi, Claudio. (1994), Comparative Analysis of Civil Service Training Schools. Maastricht: EIPA European Institutr of Public Administration. 


\section{Escolas de governo: tendências e desafios — ENAP-Brasil em perspectiva comparada \\ Regina Silvia Pacheco}

O presente texto discute as escolas de governo latino-americanas, sua origem, evolução recente e perspectivas. Para tanto, parte da história institucional da ENAP-Brasil, buscando levantar pistas de análise a serem testadas nas demais escolas. A fim de suscitar o debate, arrisca algumas generalizações para o contexto latino-americano - como a tentativa de periodização e a análise dos anos 80 . Não tem por objetivo propor a convergência dos modelos e orientações das várias escolas de governo latino-americanas; apenas quer suscitar uma reflexão de conjunto que aponte traços comuns, para ajudar a situar e ampliar o debate que se trava em cada país sobre as perspectivas destas escolas de governo.

$\mathrm{O}$ texto está organizado em sete partes. Inicia adotando uma definição para o termo "escola de governo", para fins de análise neste texto, já que seu uso corrente é vago e impreciso. A seguir, reconstrói a trajetória institucional da ENAP - Brasil, a fim de estabelecer alguns parâmetros para a análise em perspectiva comparada. Na terceira parte, entra na análise comparada, arriscando uma periodização para a história recente das escolas de governo (pós-80). Na quarta parte, analisa as escolas de governo latino-americanas nos anos 80, discutindo a influência do "paradigma ENA". Em seguida, apresenta e discute a tese de que, hoje, não cabe mais a análise em termos continentais (escolas latino-americanas $\mathrm{x}$ européias e norte-americanas), pois surge um novo agrupamento de tipos de escola, segundo a orientação que assumem frente a alguns temas centrais; para tanto, expõe e analisa a missão de nove escolas de governo. Na sexta parte, apresenta as atuais tendências das escolas de governo dos países da Commonwealth, discutindo desafios e oportunidades para as instituições latino-americanas. Finalmente, nas conclusões, sintetiza e discute desafios, estratégias e perspectivas para as escolas de governo.

\section{Escuelas de gobierno: tendencias y desafíos - ENAP- Brasil en perspectiva comparada}

\section{Regina Silvia Pacheco}

El presente texto discute las escuelas de gobierno latinoamericanas, su origen, evolución reciente y perspectivas. Para hacerlo, toma como punto de partido la historia institucional de la ENAP-Brasil, buscando descubrir pistas de análisis que sean probadas en las demás escuelas. Con el objetivo de suscitar el debate, formula algunas generalizaciones para el contexto latinoamericano - tales como la propuesta de periodización y el análisis de los años 80 . Su objetivo no es proponer la convergencia de los modelos y orientaciones de varias escuelas de gobierno latinoamericanas; busca apenas suscitar una reflexión de conjunto que señale rasgos comunes, para ayudar a situar y ampliar el debate que se produce en cada país sobre las perspectivas de estas escuelas de gobierno.

El texto está organizado en siete partes. Comienza adoptando una definición para el término "escuela de gobierno", para fines de análisis en este texto, ya que su uso corriente es impreciso. A continuación, reconstruye la trayectoria institucional de la ENAP - Brasil, buscando establecer algunos parámetros para el análisis dentro de una perspectiva comparada. En la tercera parte, hace un análisis comparado, proponiendo una periodización para la historia reciente de las escuelas de gobierno (post 80). En la cuarta parte, analiza las escuelas de gobierno latinoamericanas en los años 80, discutiendo la influencia del "paradigma ENA". A continuación, presenta y discute la tesis de que, actualmente, no corresponde hacer un análisis en términos continentales (escuelas latinoamericanas $\mathrm{x}$ europeas $\mathrm{y}$
Revista do

Serviço

Público

Ano 51

Número 2

Abr-Jun 2000

Regina Silvia

Pacheco é

presidente da

ENAP Escola

Nacional de

Administração

Pública/Brasil.

Professora

doutora da

Fundação

Getúlio Vargas,

São Paulo

(licenciada) 
norteamericanas), ya que aparece un nuevo agrupamiento de tipos de escuela, de acuerdo con su orientación en lo que se refiere a algunos temas centrales; con este objetivo, expone y analiza la misión de nueve escuelas de gobierno. En la sexta parte, presenta las actuales tendencias de las escuelas de gobierno de los países del Commonwealth, discutiendo desafíos y oportunidades para las instituciones latinoamericanas. Finalmente, en las conclusiones, sintetiza y discute desafíos, estrategias y perspectivas de las escuelas de gobierno.

\section{Civil Service Colleges: trends and challenges - ENAP - Brazil in a compared perspective \\ Regina Silvia Pacheco}

This paper presents Latin American civil service colleges, their origin, recent evolution and prospects. For this purpose, it reconstructs the institutional history of ENAP-Brazil, so as to identify analysis clues to be tested in other civil service colleges. In order to stir debate, it makes some generalizations for the Latin American colleges - such as the attempt to identify periods and analyze the 1980s. It is not intended to propose the convergence of models and guidelines to all Latin American civil service colleges, but rather to provoke a joint reflection on common traits, so as to provide an appropriate basis for and expand the debate taking place in each country on the prospects for these civil service colleges.

The paper is organized in seven sections. It begins by adopting a definition for the term "civil service college" for analysis purposes, since it is vague and imprecise as currently used. Next, it reconstructs the institutional history of ENAP - Brazil, so as to establish a few parameters for a comparative analysis. In the third section, the comparative analysis is carried out and an attempt is made to divide the recent history of civil service colleges (post-1980) into periods. In the fourth section, the paper analyses Latin American civil service colleges in the 1980s, discussing the influence of the "ENA paradigm." Next, it presents and discusses the idea that the analysis attempted herein should not to be carried out in continental terms (Latin American civil service colleges versus European and American colleges) any longer, since different types of colleges are now being grouped according to their posture in relation to some core topics, and, for this purpose, it indicates and analyses the mission of nine civil service colleges. In the sixth section, current trends of civil service colleges in Commonwealth countries are presented and challenges and opportunities for Latin American institutions are discussed. Finally, challenges, strategies and prospects for public management colleges are summarized and discussed. 